\title{
Formação inicial de pedagogos no Programa Residência Pedagógica: possibilidades de aprendizagem e desenvolvimento sobre a Gestão Escolar
}

Initial training of pedagogues in the Pedagogical Residence Program: learning and development possibilities on School Management

Etienne Henrique Brasão Martins

Poliana Hreczynski Ribeiro

Natalina Francisca Mezzari Lopes

\begin{abstract}
Resumo: Trata-se de um relato de experiência sobre as possibilidades de aprendizagem e desenvolvimento que o Programa Residência Pedagógica proporcionou para a formação inicial em gestão escolar dos residentes em Pedagogia. É um estudo descritivo, tipo Relato de Experiência, conjugado com pesquisas bibliográfica e documental aproximando conhecimentos teóricos como o da psicologia histórico-cultural e as práticas na Residência Pedagógica, durante o período de 2018 a 2020, em uma escola pública de educação de jovens e adultos localizada no município de Maringá/PR. Percebeu-se que o espaço de formação proporcionado pelo programa pode se configurar em importante instrumento para a construção da identidade do pedagogo gestor tendo na docência a base de sua formação, conforme indicado nas diretrizes curriculares do curso. As atividades e as reflexões contribuíram para a aprendizagem e desenvolvimento no tocante a aspectos pessoais e profissionais dos acadêmicos relacionados à dinâmica administrativa e pedagógica da organização do trabalho escolar enriquecendo sobremaneira a formação política e emancipatória dos futuros pedagogos.
\end{abstract}

Palavras-chaves: Pedagogo gestor. Gestão escolar. Residência em Pedagogia.

\begin{abstract}
It is an experience report on the possibilities of learning and development that the Pedagogical Residency Program provided for the initial training in school management of residents in pedagogy. It is a descriptive study, type of Experience Report, combined with bibliographic and documentary research bringing together theoretical knowledge such as that of historical-cultural psychology and practices in pedagogical residency, during the period from 2018 to 2020, in a public school for the education of young people and adults located in the city of Maringá/PR. It was noticed that the training space provided by the program can be configured as an important instrument for the construction of the identity of the managing pedagogue having in teaching the basis of their training, as indicated in the curriculum guidelines of the course. The activities and reflections contributed to the learning and development regarding the personal and professional aspects of academics related to the administrative and pedagogical dynamics of the organization of schoolwork, greatly enriching the political and emancipatory formation of future educators.
\end{abstract}

Keywords: Manager pedagogue. School management. Residence in Pedagogy. 


\section{Introdução}

Este relato decorre das experiências vivenciadas no Programa Residência Pedagógica $(\mathrm{PRP})^{1}$ em uma universidade pública do norte do Paraná, entre os anos de 2018 a 2020, que contribuíram amplamente com a formação inicial de acadêmicos do curso de graduação em Pedagogia sobre a gestão escolar. Experiências essas que se manifestaram essenciais para compreensão da teoria e da prática no trabalho da escola contribuindo com a aprendizagem e desenvolvimento em aspectos pessoais e profissionais dos acadêmicos relacionados à dinâmica administrativa e pedagógica da organização do trabalho escolar.

Um grupo de professores do curso de Pedagogia reconheceu no Programa um espaço relevante e de muitas possibilidades para a formação inicial dos futuros pedagogos. Tal espaço de formação permitiria além da preparação para a docência, vivenciar aspectos diretamente relacionados à gestão escolar em conformidade com as Diretrizes Curriculares do curso, Resolução n 1 - CNE/CP, de 15 de maio de 2006:

[...] O curso de Licenciatura em Pedagogia destina-se à formação de professores para exercer funções de magistério na Educação Infantil e nos anos iniciais do Ensino Fundamental, nos cursos de Ensino Médio, na modalidade Normal, de Educação Profissional na área de serviços e apoio escolar e em outras áreas nas quais sejam previstos conhecimentos pedagógicos (BRASIL, 2006, Art. 4).

A abrangência da formação do pedagogo extrapola o espaço de sala de aula para alcançar a organização administrativa e pedagógica da gestão da escola. No entanto, acima de qualquer delimitação da formação em Pedagogia, é importante ter presente o que diz Saviani (2008, p. 6): "a palavra 'pedagogia', e mais particularmente, o adjetivo 'pedagógico' têm marcadamente ressonância metodológica denotando o modo de operar, de realizar o ato educativo". A

\footnotetext{
1 O Programa Residência Pedagógica foi instituído pela Coordenação de Aperfeiçoamento de Pessoal de Nível Superior (CAPES), por meio da Portaria gab $n^{\circ} 38$, de 28 de fevereiro de 2018, no final da gestão presidencial de Michel Temer (31 de agosto de 2016 - 31 de dezembro de 2018), compondo a política nacional de formação de professores. O programa foi direcionado para os acadêmicos dos anos finais dos cursos de licenciatura (com $50 \%$ ou mais do curso realizado) com a possibilidade de aproveitamento de estágio aos residentes que ingressarem no programa.
} 
Pedagogia é reconhecidamente, desde Durkheim (1965) a teoria prática da educação, indicando como política norteadora de formação do pedagogo o vínculo teórico-prático. Nesse sentido, o PRP, em seus objetivos dispostos no Edital Capes n. 06/2018, mostrou-se como uma possibilidade de ampliar os espaços formativos dos acadêmicos residentes:

I. Aperfeiçoar a formação dos discentes de cursos de licenciatura, por meio do desenvolvimento de projetos que fortaleçam o campo da prática e conduzam o licenciando a exercitar de forma ativa a relação entre teoria e prática profissional docente, utilizando coleta de dados e diagnóstico sobre o ensino e a aprendizagem escolar, entre outras didáticas e metodologias (BRASIL, 2018a).

Após os trâmites legais de aprovação do programa pela CAPES, a aproximação formativa entre teoria e prática desenvolveu-se numa dinâmica marcada por dois encontros semanais: um de caráter formativo-reflexivo, realizado na própria universidade com todos os membros do núcleo (vinte e quatro residentes, três preceptoras e dois voluntários); e um outro encontro na escola-campo, caracterizado por atividades de imersão (práticas de observação participante e de intervenção), sempre acompanhado pela pedagoga-preceptora.

As atividades visaram o entrelaçamento entre a reflexão e a ação objetivando uma práxis criativa. Seguimos o sentido de práxis apresentado por Kosik (1976, p. 44) "[...] A práxis do homem não é atividade prática contraposta à teoria; é determinação da existência humana como elaboração da realidade. A práxis é ativa, é atividade que se produz historicamente" (grifos do autor). A práxis envolve a essência do ser humano, enquanto ontocriativo "[...] como ser que cria a realidade (humano-social) e que, portanto, compreende a realidade (humana e não-humana, a realidade na sua totalidade)" (1976, p. 222).

Nessa direção, a proposta de trabalho durante a Residência em pedagogia tinha como pressuposto superar a perspectiva de pensar a prática a partir de paradigmas predeterminados, mas olhar para a realidade escolar e compreendê-la em suas contradições históricas e sociais para só então indicar ações que pudessem ter como indicativo elementos de superação das condições apresentadas. Isso significava entender o caráter social da escola 
que tem como papel central do conhecimento a estrutura e a organização da sociedade (PENIN; VIEIRA, 2002 p. 13). Significava também entender o caráter de ação que o PRP propunha, que possibilitava ou não, nos colocar diante do trabalho da escola como ser ativo e criador. A pretensão não estava em fazer apologia ao domínio das práticas educativas. Para ser ativo e criador requeria entender os fundamentos da prática e da política que norteava o trabalho da escola para, então, perceber as possibilidades objetivas e subjetivas de intervenção.

O primeiro elemento provocativo para a reflexão foi compreender a educação como direitos e como deveres, conforme estabelecidos pela Constituição Federal de 1988 (CF/88):

[...] A educação, direito de todos e dever do Estado e da família, será promovida e incentivada com a colaboração da sociedade, visando ao pleno desenvolvimento da pessoa, seu preparo para o exercício da cidadania e sua qualificação para o trabalho (BRASIL, 1988, Art. 205).

Ao Estado cabe garantir o pleno desenvolvimento dos indivíduos, de forma que possam exercer a cidadania, ou seja, as formações que atendam às necessidades sociais. No entanto, os dados educacionais têm demonstrado que ainda falta muito para garantir o direito de inclusão escolar em suas diferentes formas e em seu sentido ampliado. Esse olhar provocou-nos a reflexão: é possível intervir nessa realidade como jovens residentes? Há espaço para práticas superadoras durante o Programa Residência Pedagógica na escola-campo?

Perguntas como essas, nos acompanharam nas leituras, nas discussões e nas observações participantes na escola-campo. Enquanto estudantes de Pedagogia nos preparávamos para atuar em diversas áreas do conhecimento no ensino/docência ou na área da gestão escolar. Diante das práticas que se mostrava na escola, foi necessário ressignificar os espaços de intervenção do pedagogo para não nos identificarmos como profissionais polivalentes desvinculados do exercício reflexivo e crítico diante dos desafios da educação. Observações que nos levaram a nos indagar: "Quais as possibilidades de aprendizagem e desenvolvimento teórico-prático que o Programa Residência 
Pedagógica poderia proporcionar para a nossa Formação Inicial em Pedagogia?"

À medida que as ideias, as intenções, as compreensões, as reflexões se configuravam em planejamento e aos poucos concretizavam-se na escolacampo ou na universidade, entendíamos a escola como espaço inicial e continuado de formação em ação de professores. Assim sendo, este relato tem como objetivo refletir sobre as possibilidades de aprendizagem e desenvolvimento que o PRP pode proporcionar para a formação inicial em gestão escolar aos residentes vinculados ao curso de Pedagogia.

Para essas reflexões foi utilizado o recurso de Relato de Experiência vivenciadas por parte de um grupo de residentes em Pedagogia numa escola pública de Educação de Jovens e Adultos do município de Maringá/PR vinculados a uma universidade pública da cidade, no período de 2018 a 2020. Foram inúmeras as atividades realizadas durante o programa. A escolha para este relato recaiu sobre a experiência formativa em gestão escolar, a qual colocará luz sobre a necessidade e importância do conhecimento sobre a gestão educacional e gestão escolar para a formação e atuação docente.

Pensar no Relato de Experiência como parte de uma metodologia, a partir do que diz Daltro e Faria (2019), é apontar possibilidade de criação de uma narrativa científica resultante de um entrecruzamento de processos, tanto coletivizados quanto singulares. Nesse sentido, a experiência é demarcada “[...] como objeto de análise do RE [Relato de Experiência], uma fonte inesgotável de sentidos e possibilidades passíveis de análises (DALTRO; FARIA, 2019, p. 227). De maneira mais sintética, os autores afirmam que:

Utilizar o RE como metodologia de construção de conhecimento científico, de forma descentralizada, significa abdicar da pretensão moderna do discurso unificado e total. Entretanto significa também compreender que o discurso está afetado por fatores exteriores, conscientes e inconscientes daquele que profere a palavra narrativa e tem potência de contribuição social (DALTRO; FARIA, 2019, p. 231).

A narrativa aqui apresentada discorre sobre atividades vivenciadas, tendo como suporte a pesquisa em material bibliográfico e documental, os quais permitiram cobertura de uma gama de fenômenos ampliando as 
aprendizagens construídas em ações na escola-campo (GIL, 2002). A investigação bibliográfica acompanhou toda a dinâmica de desenvolvimento do programa. Com auxílio da orientadora do programa ou de professores do curso de Pedagogia, foram delimitadas as fontes para compreender os fundamentos teóricos relacionados à educação, à escola e à aprendizagem. O diálogo com as fontes de autores clássicos como Kosik (1976) e Vigotski (2000, 2001, 2009), Leontiev $(1969,1998)$ e contemporâneos como Vieira (2007), Lara e Lopes (2017), Coelho e Volsi (2017) e Silva e Czernisz (2017) nortearam a estruturação do trabalho e a formação dos residentes.

\section{Fundamentos norteadores da formação}

A perspectiva norteadora do trabalho na escola-campo procurou seguir o referencial teórico da psicologia histórico-cultural. A escola é compreendida como um lugar de encontro de conhecimentos que, produzidos historicamente, são objetos de ensino e de aprendizagem, condição para o desenvolvimento da humanidade. Leontiev (1998, p. 291) em seus estudos mostrou que, "[...] quanto mais progride a humanidade, mais rica é a prática sócio histórica acumulada por ela, mais cresce o papel específico da educação e mais complexa é a sua tarefa" Nesse entendimento, a formação docente, ao oportunizar práticas na escola, aproxima o estudante da diversidade e complexidade educacional em sua função de oferecer a formação humana e científica necessárias para as novas gerações.

A psicologia histórico-cultural tem como pressuposto que não se nasce humano, mas sim, torna-se humano à medida que são incorporados os conhecimentos e as experiências acumulados pelo coletivo da humanidade ao longo da história (LEONTIEV, 1998). Os indivíduos são mobilizados pela relação coletiva com os mais experientes e mais desenvolvidos, e, dessa forma, têm a possibilidade de aprimorar os comportamentos essencialmente humanos.

Tais pressupostos para serem introduzidos nas práticas educativas implica em mudança de pensamento e do modo de agir. Vigotski (2001, p. 64), já dizia que o "[...] mestre deve ser os trilhos por onde se movimentam com 
liberdade e independência os vagões, que recebem dele apenas a orientação do próprio movimento". A orientação pedagógica aos residentes na escolacampo precisava romper com as características hierarquizadas de relação professor-aluno, do pensamento positivista que insere a realidade no planejamento concebido antes de conhecer a realidade escolar, como condição para compreender os limites entre direcionamento e liberdade; orientação e autonomia durante a observação, o planejamento, a organização e a execução das atividades.

Nesse sentido, partiu-se do entendimento de que as palavras importam, elas não são "[...] neutras, mas, ao contrário, engendram-se no âmbito das lutas travadas entre diferentes postulados ideológicos." (COELHO; VOLSI, 2017 , p. 107). As palavras contidas nos documentos carecem de ser contextualizadas para serem compreendidas em seu espaço-tempo. O documento, como leis, projetos, programas e outros, compõe-se de conteúdos que para uma análise crítica necessitam ser situados em seu contexto histórico de produção delimitando os envolvidos no processo de construção. Evangelista e Shiroma (2019, p. 84) alertam que muitas vezes o documento traz "[...] o conteúdo e sentido do que deve ser internalizado mistificadamente pelos sujeitos sociais, transformando-se em sua visão de mundo, alienada e degradante". Isso significa que, antes de mais nada, "produzir conhecimento sobre os documentos é produzir consciência" (EVANGELISTA; SHIROMA, 2019, p. 89).

Nessa direção, entendemos a importância de buscar "[...] o significado e a utilização apropriada de conceitos" (COELHO; VOLSI, 2017, p. 107) que norteiam a profissão do pedagogo na organização do trabalho da escola. Iniciamos pela legislação que organiza e direciona a formação e a profissão do pedagogo para delimitar o entendimento de gestão da educação e da escola, articulando com pesquisadores da área.

Ao pensar uma área de formação é essencial conhecer as Diretrizes Curriculares do Curso, no nosso caso, as do curso de Pedagogia (2006) que norteiam a formação do licenciado. $O$ documento delimita docência, 
[...] como ação educativa e processo pedagógico metódico e intencional, construído em relações sociais, étnico-raciais e produtivas, as quais influenciam conceitos, princípios e objetivos da Pedagogia, desenvolvendo-se na articulação entre conhecimentos científicos e culturais, valores éticos e estéticos inerentes a processos de aprendizagem, de socialização e de construção do conhecimento, no âmbito do diálogo entre diferentes visões de mundo (BRASIL, 2006, art. $2, \S 1^{\circ}$, grifos nossos).

A docência assim compreendida, contempla um arcabouço de conhecimentos necessários para fundamentar a ação educativa, isto é, a docência. Observa-se que as Diretrizes não tratam só de conhecimento, indicam a necessidade da articulação com a pesquisa, a produção e a prática. Esta última no sentido de aplicação na ação educativa das contribuições de diversas áreas das ciências:

[...] o Curso de Pedagogia, por meio de estudos teóricopráticos, investigação e reflexão crítica, propiciará:

[...] a aplicação ao campo da educação, de contribuições, entre outras, de conhecimentos como o filosófico, o histórico, o antropológico, o ambiental-ecológico, o psicológico, o linguístico, o sociológico, o político, o econômico, o cultural (BRASIL, 2006, art. 2, $\S 1^{\circ}$ ).

É interessante observar que as diretrizes vinculam pesquisa, conhecimento e práticas para além da sala de aula. As atividades profissionais do licenciado em Pedagogia abrangem tudo o que envolve a docência em seu vínculo com a organização da escola. As atividades formativas incluem a integração de conhecimentos da organização e gestão de sistemas e instituições de ensino que, conforme as DCN/Pedagogia, abrangem:

I - planejamento, execução, coordenação, acompanhamento e avaliação de tarefas próprias do setor da Educação;

II - planejamento, execução, coordenação, acompanhamento e avaliação de projetos e experiências educativas não-escolares;

III - produção e difusão do conhecimento científico-tecnológico do campo educacional, em contextos escolares e nãoescolares. (BRASIL, 2006, art. 4, Parágrafo Único),

As DCN/Pedagogia indicam ainda como objeto de formação do pedagogo a "[...] participação na gestão de processos educativos e na 
organização e funcionamento de sistemas e instituições de ensino" (BRASIL, 2006, Art. 3, III). A gestão se mostra como integrante da docência, reafirmando o fato que historicamente a atuação do pedagogo possui "[...] papel chave no processo educativo e na garantia da realização da função social da escola [...]" (SILVA; CZERNISZ, 2017, p. 166), cuja finalidade social e política é adequar a educação às transformações no campo econômico e político brasileiro.

Lara e Lopes (2017, p. 146) nos ajudaram a pensar a escola que, enquanto instituição educativa, tem limites e possibilidades em sua função de proporcionar "[...] aos homens o acesso, de forma sistematizada, ao saber acumulado historicamente". As autoras destacam, ainda, um importante papel da escola que é a formação para a cidadania, considerando que:

[...] diante do conhecimento sistematizado há condicionantes que trazem diferentes concepções de homem e sociedade, bem como contradições das diferentes classes sociais que constituem o contexto histórico, político, social e também material da sociedade (LARA; LOPES, 2017, p. 246).

Nessa direção, a função social da escola que, muitas vezes, fica apenas no plano de inclusão de acesso à escola, embora seja um grande avanço, precisa ser ressignificada e avançar para o direito de acesso ao ensino de qualidade conforme bem esclarece Coelho e Volsi (2017, p. 120):

[...] Entendemos que a função social e pedagógica da escola é assegurar ao seu público a apropriação dos conhecimentos historicamente produzidos pela humanidade, e assegurar seu pleno desenvolvimento cognitivo, ético e moral.

A delimitação da função social da escola contribuiu para a percepção do caminho no qual a gestão está vinculada. Como aponta Coelho e Volsi (2017, p. 108), a gestão se atrela "[...] às questões de planejamento, organização, execução e avaliação de objetivos político-pedagógicos propostos no âmbito da educação nacional e da escola", para a realização de determinados fins, sempre orientados para a efetivação do ensino e da aprendizagem (SILVA; CZERNISZ, 2017).

A gestão escolar está vinculada à gestão educacional. De maneira mais específica, a gestão educacional compreende tanto o sistema de ensino quanto a escola como responsável para organizar o nível macro da educação. A 
gestão de sistema "[...] compreende o ordenamento normativo e jurídico, o financiamento e a vinculação de instituições sociais por meio de diretrizes comuns" (COELHO; VOLSI, 2017, p. 115). Ao que se relaciona a gestão escolar, os mesmos autores afirmam:

A gestão escolar refere-se à forma de organizar o funcionamento da escola, quanto aos aspectos políticos, administrativos, financeiros, culturais e pedagógicos, com o intuito de dar transparência as suas ações. Diz respeito às questões específicas da escola, sua realidade, seus objetivos, necessidades e desafios (COELHO; VOLSI, 2017, p. 120).

Dessa forma, compreende-se a gestão escolar não somente como organizadora das condições para o trabalho docente, mas também como parte integrante da docência. A atividade realizada por gestores é diferente dos professores em sala de aula, todavia está vinculada aos mesmos fundamentos e princípios pedagógicos da docência uma vez que sua função é organizar condições para o ensino e a aprendizagem, conforme delimitado no projeto da escola. Numa escola que visa a inclusão pedagógica, o diretor assume uma posição de interlocutor das teorias, das práticas, dos desejos e sonhos para compor o diálogo necessário de uma organização da cultura política e democrática inclusivas.

O delineamento da gestão da escola que tem por base a docência faz pensar no perfil do profissional que cumpre a função de diretor(a). Impõe-se um amplo olhar histórico, cultural e político para a formação do pedagogo uma vez que, conforme Silva e Czernisz "[...] o curso de Pedagogia deverá assegurar as bases para a articulação entre docência, a gestão educacional, além da produção de conhecimento na área da educação" (2017, p. 169).

O PRP possibilitou condições para pensar na formação do pedagogo na dinâmica da gestão da escola e nos processos educativos. Ampliar as possibilidades de formação dos acadêmicos em Pedagogia durante a Residência para o âmbito da gestão, implicou em reconhecer: o perfil desse profissional dado em seu currículo e legislação; a importância da escola como espaço de pesquisa e formação; e reconhecer a Pedagogia como alicerce da valorização da cultura e da prática educativa. 


\section{Vivências em gestão escolar durante o Programa Residência Pedagógica no subprojeto da Pedagogia}

Durante os dezoito meses do programa (agosto/2018 a janeiro/2020), a dinâmica de organização das atividades foi composta por encontros semanais formativos-reflexivos, com duração de quatro horas cada, realizados na universidade, e por encontros formativos na prática pedagógica, também com quatro horas cada, cumpridos na instituição de ensino de educação de jovens e adultos da rede pública.

Os encontros na universidade remetiam-se à reflexão e compreensão das vivências na escola-campo que envolviam uma sucessão de relações entre pessoas como, por exemplo, professores, gestores, equipe de apoio técnico e administrativo, alunos e comunidade. Envolviam, também, a relação com as orientações emanadas do sistema de educação ou da rede de ensino na qual a escola estava vinculada. As reflexões contaram com contribuições de educadores como Anísio Teixeira (1962) e Fernando de Azevedo et al (2010), fazendo o movimento do contexto escolanovista ao momento atual, atentando não só para a formação do estudante da Educação Básica, mas também para a própria formação enquanto futuros docentes e/ou pedagogos gestores.

Quanto aos encontros formativos-práticos na escola-campo, tudo parecia nebuloso no início das atividades. Chegando na instituição de ensino, a atividade foi conhecer a dinâmica e a organização dos espaços nos quais estaríamos nos próximos dezoito meses, que se mostrou bem distinta daquela já vivenciada anteriormente em estágios obrigatórios do curso.

O trabalho na escola, à primeira vista, se mostrava como um conjunto de pessoas seguindo um roteiro de ações numa dinâmica condicionada a protocolos que deveriam ser seguidos. Cada funcionário na escola executava sua função com muita determinação, no entanto, percebíamos de forma isolada e individualizada, como se tivessem apenas cumprindo determinações ou orientações emanadas externamente. Os movimentos dos estudantes na escola se mostravam como necessidade de ajustar-se em todo aquele emaranhado de normas e regras para conseguir a aprovação nas disciplinas e concluir o Ensino Fundamental ou/e Ensino Médio. 
Esse olhar provocou preocupação, insegurança e inquietação, indagando-nos: é possível intervir nessa realidade como jovens residentes? Há espaço para práticas pedagógicas superadoras durante nosso tempo na escola-campo?

Após diálogo e preparação nos encontros formativos na universidade, foram realizadas observações, participações e intervenções na dinâmica da gestão escolar envolvendo a preceptora, o gestor e toda a comunidade da escola-campo. Antes da intervenção os residentes desenvolveram um amplo estudo da cultura organizacional da escola-campo abrangendo a história da instituição de ensino vinculada à história da luta em defesa da Educação de Jovens e Adultos; as políticas públicas da EJA em seus aspectos administrativos e financeiros; as concepções que nortearam os processos de ensino daqueles que não tiveram acesso à educação em idade própria; e a dinâmica das relações com a rede mantenedora e com o sistema de educação.

Para o estudo foram selecionadas as legislações da educação brasileira como CF/1988, a LDB 9394/96, as Diretrizes Curriculares da EJA/PR/2006, o Projeto Político Pedagógico (PPP) da escola-campo e os regulamentos internos. Conhecer as legislações e os documentos dão ferramentas para observar a dinâmica da organização da escola, a qual apresentou-se como necessidade premente a ser refletida e isso implicava em entender a gestão dos processos educativos e suas relações com a gestão do sistema educacional. Recorremos a estudos, como enunciados no item anterior desse relato, que contribuíssem para tais entendimentos, uma vez que,

[...] o educador precisa ter condições teóricas de fazer a leitura do projeto político pedagógico em curso, o qual se desenvolve a partir do campo produtivo. Este seria o ponto de partida para pensar a escola e a atuação do pedagogo gestor numa perspectiva emancipatória (SILVA; CZERNISZ, 2017, p. 169).

Os estudos dos documentos permitiram a compreensão ampliada da configuração da escola para além de sua estrutura e espaços educativos. Compreendemos que a prática pedagógica realizada no quotidiano da escola está diretamente interligada às normas e as intencionalidades oriundas do sistema. Essa interligação não é apenas de forma determinativa, observamos 
que a escola compõe o sistema o que pode significar que há espaço para construção de políticas a partir da escola. Assim, foi possível identificar a escola como um espaço de lutas, de vivências, de expressão dos princípios da gestão pública e de aprendizagens de forma interligada: sala de aula e gestão; educadores e comunidade.

Um dos espaços de participação ativa dos residentes foi marcado pelas discussões no processo de reformulação do PPP cuja finalidade era atender as orientações da Base Nacional Comum Curricular (BNCC) e o Referencial Curricular do Estado Paraná. O trabalho exigiu revisitar os conceitos os princípios, direitos e fundamentos que norteariam o projeto da escola. Tal ação culminou no entendimento da escola de Educação de Jovens e Adultos como ambiente de luta em defesa da inclusão social, cultural e política de todos que por ela passariam.

Os estudos, reflexões e debates realizados com a participação dos residentes durante o trabalho de reformulação do PPP contribuiu para o entendimento de que o trabalho da gestão da escola assenta-se em três eixos fundamentais: política educacional, gestão educacional e gestão escolar. Nos estudos das Leis e normatizações identificaram-se como as intenções do Estado são traduzidas em política educacional; nos estudos relacionados aos programas da EJA, ao financiamento, à merenda escolar, ao livro didático entre outros, levantaram-se as intenções governamental "colocadas" em ação em nível macro, conhecida como a gestão educacional; e, por fim, ao olhar para a organização da escola, seus programas de ensino, normas, regulamentações, diretrizes entre outros elencou-se intenções governamentais (de nível federal ou estadual) que se expressam em ação em nível micro, ou seja, na organização escolar.

Nesse caminho teórico-prático, a escola mostrou-se muito mais que um espaço de implantação das políticas públicas, mas, conforme indicado por Vieira (2007), como o local da demanda, da avaliação e da construção de políticas educacionais. A ação da escola é ação pública, isso significa dizer que deve ser norteada pelos princípios administrativos das condições de 
implementação, do valor público (a democracia) e das condições políticas (VIERA, 2007).

A partir desse estudo e atividades práticas os residentes organizaram um plano de aula cuja finalidade era apresentar a Escola de Educação de Jovens e Adultos. Com duração de aproximadamente $1 \mathrm{~h}$ os residentes prepararam a aula contemplando as seguintes indagações: $O$ que é a escola de Educação e Jovens e Adultos? Quando e por que surge a necessidade dessa modalidade de ensino? Como as políticas e os programas chegam até a escola? Há interferência das políticas públicas na organização da escola? Qual a metodologia do ensino na EJA? Sempre foi assim? Qual o significado social da escola?

Trabalhamos com o conceito de docência-expandida, aquela que abrange não só aqueles que estão na sala de aula, mas todos aqueles que tem relação com a educação: funcionários, família, estudante, professores, estagiários e assim por diante. Nesse sentido, as aulas extrapolaram os conteúdos curriculares para explorar os aspectos políticos que interferem na organização do cotidiano da escola por meio das intenções engendradas na formatação pedagógica. Foram organizados vários encontros com estudantes da EJA; educadores (professores e funcionários) da escola; e estagiários do curso de Pedagogia da universidade. Em cada encontro foi adotado a dinâmica da apresentação oral com o uso de Power Point $\circledast$, seguido da visita administrativa e pedagógica pelos espaços da escola, finalizando com depoimentos sobre a história de vida de alguns dos estudantes da EJA enchendo de emoção e sensibilidade o tema "inclusão social".

Essa atividade, demonstrou amplas possibilidades de aprendizagens e desenvolvimento sobre a gestão escolar durante o PRP em Pedagogia. Além disso, desvelou a importante e complexa abrangência da atuação do pedagogo na função de coordenação e de acompanhamento do trabalho das pessoas na escola. Segundo Libâneo, Oliveira e Toschi (2003, p. 293) a gestão escolar compreende "ações e procedimentos destinados a reunir, a articular e a integrar as atividades das pessoas que atuam na escola, para alcançar objetivos comuns" conforme dispostos no projeto da instituição. Para este 
acompanhamento, o pedagogo-gestor atua de diferentes maneiras naquilo que envolve a mediação entre conhecimento científico e o conhecimento já agregado pelos estudantes, docentes, responsáveis e funcionários envolvidos na instituição. Isso porque o conhecimento não é estanque, existe uma totalidade entre os contextos históricos, políticos e sociais que possibilita compreender os fenômenos educativos na formação, assim:

A aprendizagem e o desenvolvimento, ainda que diretamente ligados não se processam simetricamente. O desenvolvimento não é estanque, nem acompanha a aprendizagem como uma sombra acompanha o objeto que a projeta (VYGOTSKY, 2001, p. 79).

O pedagogo na gestão escolar necessita dedicar tempo aos alunos da EJA para a escuta de suas angústias, experiências de vida, alegrias e motivações que formam a sua identidade como sujeitos e assim orientá-los para a relação dinâmica e complexa entre a aprendizagem e o seu desenvolvimento, aproximando a escola de seu meio social. A escuta mediada pela ação pedagógica foi outra atividade desenvolvida pelos residentes. A metodologia adotada foram oficinas culturais a partir de temáticas surgidas nas "conversas" informais com os estudantes ou por necessidades de aprendizagens indicadas pelos professores. Entre as temáticas inclui-se oficina de Poesia de Cecília Meireles e Setembro Amarelo.

As atividades teórico-práticas elencadas tinham como finalidade "[...] elaboração de estratégias apropriadas e adequadas para mudar as condições objetivas de reprodução, como para a automudança consciente dos indivíduos" (MÉSZÁROS, 2008, p. 65, grifos do autor). Ou seja, as práticas e as estratégias planejadas foram essenciais para compreender as possibilidades de intervenção do pedagogo-gestor na organização de um projeto político e pedagógico para a escola pública de Educação de Jovens e Adultos.

Pensando a organização de uma escola democrática a "[...] elaboração e a execução de uma proposta pedagógica é a primeira e principal das atribuições da escola, devendo sua gestão orientar-se para tal finalidade" (VIEIRA, 2007, p. 62). A gestão escolar parte de processos democráticos para a organização sistematizada da instituição educativa, sem perder de vista os 
documentos deliberativos, como a Constituição Federal/1988 e a LDB/1996, assim como as Diretrizes Curriculares até culminar no documento organizador da unidade de ensino: seu Projeto Político e Pedagógico.

Ao término do período do PRP em Pedagogia a compreensão da organização da gestão da escola-campo, sua função social e sua relação com o sistema de educação abriu um universo de possibilidades e de intervenções aos residentes. As relações na escola já não pareciam desorientadas e isoladas, a vida escolar passou a ter sentido enquanto um sentimento que "aprofunda, amplia e purifica a vida emocional” (VIGOTSKI, 2009, p. 96) e também significado enquanto aquele sentimento que permite "[...] exercitar seus ímpetos e capacidades criadoras, dominar a fala humana" (VIGOTSKI, 2009, p. 96). Para o residente, a profissão pedagogo-gestor passou a ter sentido e o significado desenvolvendo uma identidade profissional de professor que inclui a gestão e a organização escolar.

Por fim, percebe-se que o conhecimento adquirido sobre a organização da escola e sua função social, em seus aspectos teóricos e práticos, transformou a percepção sobre a educação e suas relações de trabalho. Em outras palavras, mudou-se a percepção da profissão professor-pedagogo, docência e gestão não são polos opostos de atuação, são partes de um mesmo processo educativo.

\section{Considerações finais}

Diante do exposto, retoma-se a questão inicial: Quais as possibilidades de aprendizagem e desenvolvimento que o Programa Residência Pedagógica proporcionou na Formação Inicial dos pedagogos gestores? Nesse percurso, foi possível constatar que várias foram as possibilidades para a formação inicial de pedagogos gestores e a relevância do PRP em proporcioná-la na práxis pedagógica.

Com a experiência aqui relatada foi possível compreender a relevância da formação política, teórica e das práticas de ensino e práticas educacionais como saberes necessários para o desempenho da função do pedagogo na gestão e/ou na docência. As ações pedagógicas realizadas na escola-campo, 
antecedidas por estudos e reflexões e seguidas por avaliações, realizavam-se no movimento de reflexão-ação. As ações realizaram-se como práxis (reflexão constante da teoria prática em sentido de prática-teoria-prática) num processo importante dentro do ambiente escolar, que tornaram viável práticas pedagógicas emancipadoras. Nessas ações, o ensino e a gestão aproximaramse acompanhando o trabalho do pedagogo-gestor em sua cotidianidade. De forma resumida, o acesso à forma como as instituições de ensino se organiza nas esferas políticas, administrativas e pedagógicas fez parte das observações dos residentes. Entre as funções da escola está a necessidade de construir uma base teórica que dê sustentação ao PPP e que norteará a parte mais técnica da organização da escola como o Regimento. Ambos são essenciais para a coesão no trabalho pedagógico que se expressa no Plano de Trabalho Docente, na dinâmica administrativa e nas relações de trabalho da escola.

Essas experiências produziram "[...] um sentido para o estudante e o seu conteúdo lhe interessa e responde ao que deseja conhecer; o que depende dos motivos da sua atividade" (LEONTIEV, 1969, p. 351), ou seja, conhecendo a realidade educacional, favoreceu a motivação para estudar as legislações, documentos da escola e a base teórica que sustenta as ações gestoras educativas para construir caminhos e estratégias no exercício do trabalho do pedagogo-gestor.

O Programa Residência Pedagógica 2018/2020, com um ano e meio de duração, realizou sua primeira edição em meio dificuldades, incertezas e muitos temores. No entanto, ao olhar para as experiências vivenciadas é possível afirmar que foram primordiais para a formação inicial dos residentes. O programa proporcionou experiências exitosas por meio dos encontros semanais orientados na universidade e na escola-campo, acentuando a reflexão sobre as ações, impactando diretamente na formação dos primeiros traços da identidade profissional dos residentes. Isso só foi possível, pela presença constante dos "mestres" (no sentido vigotskiniano): a docente coordenadora e as preceptoras; para que pudéssemos experienciar o trabalho do pedagogo gestor e contribuir com as aprendizagens na educação escolar, como também, com o desenvolvimento dos graduandos. 


\section{Agradecimento}

O estudo contou com o financiamento da Coordenação de Aperfeiçoamento de Pessoal de Nível Superior - CAPES por meio do Programa Residência Pedagógica, Edital CAPES n. 06/2018.

\section{Referências}

AZEVEDO, Fernando de et al. Manifestos dos pioneiros da Educação Nova (1932) e dos educadores (1959). Recife: Fundação Joaquim Nabuco, Editora Massangana, 2010. p. 122.

BRASIL. Constituição (1988). Constituição da República Federativa do Brasil. Brasília, DF: Senado Federal: Centro Gráfico, 1988.

BRASIL. Lei de Diretrizes e Bases da Educação Nacional. Lei número 9394, 20 de dezembro de 1996.

BRASIL. Ministério de Educação e Cultura. Parecer CEB 11/2000. Diretrizes curriculares nacionais para a educação de jovens e adultos. Brasília: MEC, 2000.

BRASIL. Conselho Nacional de Educação, Resolução CNE/CP n 1, de 15 de maio de 2006. Institui Diretrizes Curriculares Nacionais para o Curso de Graduação em Pedagogia, licenciatura. Diário Oficial da União, Brasil, 2006.

BRASIL. Edital CAPES 06/2018. Chamada Pública para apresentação de propostas no âmbito do Programa de Residência Pedagógica. Brasília, DF: Coordenação de aperfeiçoamento de pessoal de Nível Superior - CAPES, [2018a]. Disponível em: https://www.gov.br/capes/ptbr/assuntos/noticias/capes-publica-editais-do-pibid-e-do-novo-programa-deresidencia-pedagogica. Acesso em: 20 ago. 2020.

BRASIL. Ministério da Educação. Base Nacional Comum Curricular - BNCC $2^{a}$ versão. Brasília, DF, 2018b.

BRASIL. Portaria No 38, de 28 de fevereiro de 2018. Institui o Programa de Residência Pedagógica. Brasília, DF: Coordenação de aperfeiçoamento de pessoal de Nível Superior - CAPES, [2018c]. Disponível em: https://www.gov.br/capes/pt-br/centrais-de-conteudo/01032018-portaria-n-38de-28-02-2018-residencia-pedagogica-pdf/view. Acesso em: 20 ago. 2020.

COELHO, Marcos Pereira; VOLSI, Maria Eunice França. Bases legais da gestão democrática da educação e da escola. In: NOMA, Amélia Kimiko; TOLEDO, Cézar de Alencar Arnout. (org.). Políticas públicas e educação escolar no brasil. Maringá: Eduem, 2017. p. 107-128. 
DALTRO, Mônica Ramos; FARIA, Anna Amélia de. Relato de experiência: Uma narrativa científica na pós-modernidade. Estudos e Pesquisa em Psicologia, Rio de Janeiro, v. 19, n. 1, p. 223-237, 2019.

DURKHEIM, Émile. Educação e sociologia. São Paulo: Melhoramentos, 1965.

EVANGELISTA, Olinda; SHIROMA, Eneida Oto. Subsídios teóricoMetodológicos para o trabalho com documentos de política educacional: Contribuições do marxismo. In: CÊA, Georgia; RUMMERT, Sonia Maria; GONÇALVES, Leonardo (org.). Trabalho e educação: interlocuções marxistas. Rio Grande: Ed. da FURG, 2019. p. 83-120.

GIL, Antonio Carlos. Como elaborar projetos de pesquisa. 4. ed. São Paulo: Atlas, 2002.

KOSIK, Karel. Dialética do concreto. 7.ed. Trad. Célia Neves e Alderico Toribio. Rio de Janeiro: Paz e Terra, 1976.

LARA, Angela Mara de Barros; LOPES, Lindicéia Batista de França. Os professores da educação e a função social da escola. In: NOMA, Amélia Kimiko; TOLEDO, Cézar de Alencar Arnout. (org.). Políticas públicas e educação escolar no brasil. Maringá: Eduem, 2017. p. 145-162.

LEONTIEV, Alexei Nikolaevich. Las necessidades y los motivos de la actividad. In: SMIRNOV, A. A. et al (org.). Psicologia. México: Grijalbo, p.341-354, 1969.

LEONTIEV, Alexei Nikolaevich. O homem e a cultura. In: LEONTIEV, Alexei Nikolaevich. O desenvolvimento do psiquismo. São Paulo: Editora Moraes, 1998. p. 277-302.

LIBÂNEO, José Carlos; OLIVEIRA, João Ferreira de; TOSCHI, Mirza Seabra. Educação Escolar: políticas, estrutura e organização. São Paulo: Cortez, 2003.

MÉSZÁROS, István. A educação para além do capital. 2. ed. São Paulo: Boitempo, 2008.

PARANÁ. Diretrizes Curriculares da Educação de Jovens e Adultos. 2006. Disponível em: http://www.educadores.diaadia.pr.gov.br/arquivos/File/diretrizes/dce eja.pdf.

Acesso em: 14 ago. 2020.

PARANÁ. Referencial curricular do Paraná: princípios, direitos e orientações. $2018 . \quad$ Disponível em: http://www.educadores.diaadia.pr.gov.br/arquivos/File/bncc/2018/referencial_cu rricular_parana_cee.pdf. Acesso em: 14 set 2020

PENIN, Sonia Teresinha de Sousa; VIEIRA, Sofia Lerche. Refletindo sobre a função social da escola. In: VIEIRA, Sofia Lerche (Org.). Gestão da escoladesafios a enfrentar. Rio de Janeiro: DP\&A, 2002, p.13-43. 
SAVIANI, Dermeval. Histórias das ideias pedagógicas no Brasil. 2 ed. rev. e ampl. Campinas, SP: Autores Associados, 2008.

SILVA, Ana Lucia Ferreira da; CZERNISZ; Eliane Cleide da Silva. Atuação do pedagogo gestor na educação básica. In: NOMA, Amélia Kimiko; TOLEDO, Cézar de Alencar Arnout. (org.). Políticas públicas e educação escolar no brasil. Maringá: Eduem, 2017. p. 163-179.

TEIXEIRA, Anísio. Notas para a história da educação. Revista Brasileira de Estudos Pedagógicos. Rio de Janeiro, v. 37, n. 85, jan./mar. 1962. p. 181188. Disponível em: http://www.bvanisioteixeira.ufba.br/artigos/notas2.html. Acesso em: 05 set. 2020.

VIEIRA, Sofia Lerche. Políticas e gestão da educação básica: revisitando conceitos simples. Revista Brasileira de Política e Administração da Educação-Periódico científico editado pela ANPAE, v. 23, n. 1, 2007. p. 5369. Disponível em: https://www.seer.ufrgs.br/rbpae/article/view/19013/11044 Acesso em: 11. ago. 2020.

VIGOTSKI, Lev Semenovich. A construção do pensamento e da linguagem. São Paulo: Martins Fontes, 2000.

VIGOTSKI, Lev Semionovich. Imaginação e criação na Infância: ensaios comentados. São Paulo: Ática, 2009.

VIGOTSKI, Lev Semenovich. Psicologia pedagógica. São Paulo: Martins Fontes, 2001.

\section{Sobre os autores}

\section{Etienne Henrique Brasão Martins}

ettibrasao@gmail.com

Graduado em Pedagogia pela Universidade Estadual de Maringá (UEM). Participou como bolsista: no Programa Institucional de Bolsas de Iniciação à Docência (PIBID, 2017-2018) e no Programa Institucional de Bolsas de Iniciação Científica (PIBIC, 2018-2019); além de voluntário no Programa Residência Pedagógica em Pedagogia núcleo Gestão Escolar (ag./2018jan./2020). Atualmente, integrante do Núcleo de Pesquisa e Estudo em Diversidade Sexual - NUDISEX e do Projeto de Ensino em Gestão Escolar: leituras sobre Anísio Teixeira. Desenvolve estudos na linha de pesquisa de Formação de Professores, Gestão Escolar e Gênero, entre outros estudos.

\section{Poliana Hreczynski Ribeiro}

pollyannahre@hotmail.com

Mestranda em Ensino no Programa de Pós-Graduação em Educação - PPE, na Universidade Estadual de Maringá - UEM, bolsista CAPES-UEM e Representante Discente do Mestrado no Conselho Acadêmico do PPE/UEM. Graduada em Pedagogia pela mesma Universidade e residente bolsista no 
Programa Residência Pedagógica em Pedagogia núcleo Gestão Escolar (ag./2018-jan./2020).

\section{Natalina Francisca Mezzari Lopes}

natalinamezzari@hotmail.com

Pedagoga desde 1986, mestrado em Educação pela Universidade Estadual de Campinas (2002) e doutorado em Educação Escolar pela Universidade Estadual Paulista Júlio de Mesquita - Araraquara (2017). Atuou como Professor- Pedagogo em escola Pública do PR, com passagem na gestão da educação e da escola. Atualmente é professor adjunto da Universidade Estadual de Maringá, vinculada ao Departamento de Fundamentos da Educação. Trabalhou com o PIBID e o Residência Pedagógica em Gestão Escolar. Experiência de pesquisa nos seguintes temas: Educação e trabalho, políticas de educação, estágio curricular, gestão educacional e gestão escolar. 